\title{
Phenotype, molecular characterisation and risk factors for postoperative meningitis caused by ESBL-producing- Enterobacteriaceae: a six years multi-Centre comparative cohort study
}

Guanghui Zheng ${ }^{1+}$, Yanfei $\mathrm{CaO}^{2+}{ }^{+}$, Chunhong Liu ${ }^{3+}$, Lingye Qian ${ }^{1}$, Yumeng Cai ${ }^{1}$, Miaomiao Cuii ${ }^{4}$, Huiting Sun ${ }^{3}$, Lv Hong ${ }^{1}$, Jun Yuan ${ }^{4 *}$, Lina Zhang ${ }^{2^{*}}$ and Guojun Zhang ${ }^{{ }^{*}}$

\begin{abstract}
Background: To determine the phenotype, molecular characterisation and risk factors of postoperative meningitis induced by Extended-spectrum $\beta$-lactamase (ESBL)-producing Enterobacteriaceae (EPE) in China.

Methods: We performed a multi-centre comparative cohort study of postoperative meningitis patients infected with Enterobacteriaceae in 4 neurosurgical centres in China from January 2014 to December 2019. Phenotype and molecular characteristics of the isolates were reviewed and tested, and independent risk factors of the EPE meningitis were evaluated by binary logistic regression.

Results: In total, 220 Enterobacteriaceae include 78 EPE were available in this study. 85.6\% (67/78) ESBL-related genes were tested, and $b a_{S H V}(14.9 \%)$ and $b / a_{S H V}+b l a_{T E M}+b l a_{C T X-M-9}(20.9 \%)$ were found to be the most frequent mono and combined ESBL-related genes harboured by Enterobacteriaceae. On binary logistic analysis, craniotomy (OR. 2.583, 95\% C.I. 1.274-5.235, $P=0.008$ ) and malignancy (OR. 2.406, 95\% C.I. 1.299-4.456, $P=0.005$ ) were the associated independent risk factors to meningitis induced by EPE.

(Continued on next page)
\end{abstract}

\footnotetext{
*Correspondence: junyuan99430@163.com; zhanglina9@126.com;

zgjlunwen@sina.com

${ }^{\dagger}$ Guanghui Zheng, Yanfei Cao and Chunhong Liu contributed equally to this

work.

${ }^{4}$ Department of Clinical Diagnosis, Laboratory of the Second People's

Hospital of Guiyang, Guiyang, China

${ }^{2}$ Daqing Oilfield General Hospital Clinical Laboratory, No. 9 Zhongkang

Street, Saltu District, Daqing, China

'Department of Clinical Diagnosis, Laboratory of Beijing Tiantan Hospital and

Capital Medical University, NO. 119 Nansihuan West road, Fengtai district,

Beijing, China

Full list of author information is available at the end of the article
}

(c) The Author(s). 2021 Open Access This article is licensed under a Creative Commons Attribution 4.0 International License, which permits use, sharing, adaptation, distribution and reproduction in any medium or format, as long as you give appropriate credit to the original author(s) and the source, provide a link to the Creative Commons licence, and indicate if changes were made. The images or other third party material in this article are included in the article's Creative Commons licence, unless indicated otherwise in a credit line to the material. If material is not included in the article's Creative Commons licence and your intended use is not permitted by statutory regulation or exceeds the permitted use, you will need to obtain permission directly from the copyright holder. To view a copy of this licence, visit http://creativecommons.org/licenses/by/4.0/ The Creative Commons Public Domain Dedication waiver (http://creativecommons.org/publicdomain/zero/1.0/) applies to the data made available in this article, unless otherwise stated in a credit line to the data. 
(Continued from previous page)

Conclusions: To the best of our knowledge, this is the largest series focusing on risk factors of EPE meningitis which has been conducted in China. Craniotomy and malignancy were independent risk factors for EPE meningitis. The risk factors identified may be further utilized in clinical practice and research to avoid and reduce the mortality in future.

Keywords: ESBL, Enterobacteriaceae, Meningitis, Molecular characterisation, Risk factor

\section{Background}

Postoperative meningitis, secondary to neurosurgical procedures, trauma, or shunt devices, is one of common healthcare-associated infections, which are a significant cause of perioperative morbidity, mortality and healthcare cost $[1,2]$. Incidence of postoperative meningitis in recent prospective studies varied between 0.7 and 25\% [3-6]. In recent years, postoperative meningitis has been found to be closely related to the success of neurosurgical operation and mortality of neurosurgery patients; therefore, it has received increasing attention in clinical settings. Patients who underwent neurosurgery are known to have lower immunity, experience complicated longer duration of operations, and are more difficult to treat [7]. Therefore, reducing the incidence of postoperative meningitis is an important task for neurosurgical physicians.

Various pathogens can cause postoperative meningitis, of which, and Enterobacteriaceae is a critical branch. Enterobacteriaceae has been reported to account for more than $20 \%$ of nosocomial infections [8]. Multidrugresistant Enterobacteriaceae are more harmful due to their extensive drug resistance. Extended-spectrum $\beta$ lactamase (ESBLs) production is one the most common antibiotic resistance mechanism of Enterobacteriaceae, and ESBL-producing Enterobacteriaceae (EPE) has been an increasingly implicated as a cause of infection. A previously study reported that prevalence of EPE rectal colonisation in healthy human beings was $14 \%$ globally, and the distribution varied extremely in different locations [9]. Also, EPE, as a nosocomial pathogen, is a health threat among medical institutions, especially in surgery patients with immune-compromised or other comorbidities. In 2017, the WHO released a list of antibioticresistant bacteria that pose the greatest threat to human health, and for which new antibiotics are desperately needed. From that, EPE belongs to the first-grade priority (critical) and is a clinically ultra-threatening pathogen [10]. The risk factors for EPE include prolonged mechanical ventilation [11], ICU admission [12], catheter usage [13], severe illness [14], and frequent antibiotic usage [15]. However, few reports are target on risk assessment of postoperative meningitis. Existence of the blood-brain barrier may block antibiotics such as polymyxin B entering the central nervous system, and lead to EPE postoperative meningitis more harmful [16], therefore, risk factor assessment possess great clinical significance.

To better prevent and determine the treatment strategy of postoperative meningitis caused by EPE, we conducted a multi-centre comparative cohort study to explore the independent risk factors and assess clinical molecular characteristics of postoperative meningitis caused by EPE. To our knowledge, this is the first study globally to assess the molecular characteristics of EPE and risk factors of EPE postoperative meningitis.

\section{Methods \\ Study design}

A comparative cohort study was performed at four neurological centres in China, including Beijing Tiantan Hospital and Capital Medical University, Sanbo Brain Hospital and Capital Medical University, Daqing Oilfield General Hospital and The Second People's Hospital of Guiyang between Jan 2014 and Dec 2019. The EPE molecular characteristics test of this study was approved by the ethical committee of Beijing Tiantan Hospital and Capital Medical University (KY-2019-095-03).

\section{Patients}

In the four centres, adult neurosurgical patients $(>18$ years old) were included if they were survived at least 7 days with at least one cerebrospinal fluid (CSF) culture positive for Enterobacteriaceae. Patients who underwent only external ventricular drain (EVD) or CSF shunt or stereotactic surgery, without antimicrobial therapy not done in hospital and incomplete clinical medical records were excluded. All of the patients were followed-up for the diagnosis of postoperative meningitis during the first 30 days after neurosurgery. A flow chart of this study is shown in Fig. 1.

Patients with Enterobacteriaceae postoperative meningitis were diagnosed by the diagnostic criteria of the Centres for Disease Control [17, 18]. The criteria of Enterobacteriaceae meningitis was as follows: 1) Enterobacteriaceae cultured from neurosurgical patients' CSF; 2) one or more of the clinical symptoms or signs, including fever $\left(>38^{\circ} \mathrm{C}\right)$, headache, meningeal signs (stiff neck, cranial nerve signs or irritability), with anti-infective treatment; and one or more of the clinical laboratory 


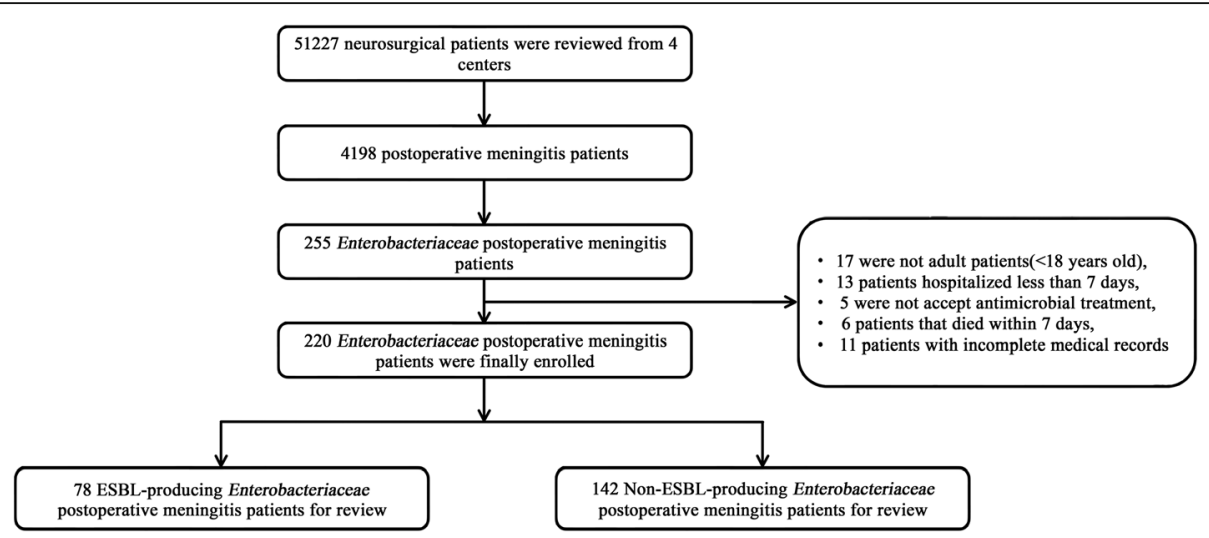

Fig. 1 Flow chart of the selection of Enterobacteriaceae postoperative meningitis patients

tests as follows: 1) elevated CSF protein level, increased CSF leucocyte count, and/or decreased CSF glucose level; 2) appearance of gram-negative bacillus on gram stain of CSF; 3) growth of Enterobacteriaceae in patients' blood (by bacterial culture).

\section{Microbiology}

All bacteria with the same growth characteristics of Enterobacteriaceae were classified to standard microbial identification procedure, and the identification system is VITEK-2 Compact system ((bioMerieux, Marcy l 'etoile, France, based on biochemical reaction) and VITEK MS (bioMerieux, Marcy l 'etoile, France, based on matrixassisted laser desorption/ionization time-of-flight mass spectrometry) system. Antimicrobial testing of susceptibility (AST) of Enterobacteriaceae was performed by the disc diffusion tests (Kirby-Bauer method) and broth microdilution method (MIC) and classified as sensitive, intermediate and resistant according to the Clinical and Laboratory Standards Institute (CLSI) 2019. Isolates tested with aztreonam or ceftazidime MICs $>1 \mathrm{mg} / \mathrm{L}$ were screened for the presence of ESBL. Judgment of an ESBL phenotype of four Enterobacteriaceae (Klebsiella pneumoniae, Klebsiella oxytoca, Escherichia coli and Proteus mirabilis) was performed by Kirby-Bauer method according to the CLSI 2019. The test procedure is as follows: ceftazidime/clavulanate and cefotaxime/clavulanate discs, in comparison with ceftazidime and cefotaxime discs alone (Oxoid Ltd., Basingstoke, Unite Kingdom). According to the CLSI 2019 antimicrobial susceptibility testing standards [19], EPE was defined when an increase in a zone diameter $\geq 5 \mathrm{~mm}$ for either antibiotic together with clavulanate vs the zone diameter of the agent, and it is reported that the ESBL phenotype of other Enterobacteriaceae can also be determined by the same method as the above four Enterobacteriaceae [20]. The left were defined as non-ESBL-producing Enterobacteriaceae (NEPE).
Molecular detection of $b l a_{C T X-M-1}, b l a_{C T X-M-9,}, b l a_{S H V}$, $b_{\text {bEM }}$, bla $_{\text {OXA-23 }}$ and bla $a_{O X A-66}$ were done by micro/ nanofluidic chip platform (MNCP) based on the loopmediated isothermal amplification (LAMP) method [21]. The extraction of the nucleic acid was done according to MNCP manufacturer's instructions. In addition, preparation of the isothermal amplification reaction solution and detection using the MNCP were the same as previously described [22].

\section{Therapy and clinical variables for evaluation}

In this study, all of the patients' qualified daily progress records were established by analyse of the clinical database of the neurosurgery, infectious diseases and microbiology departments in the four centres described above. From that, we summarised and measured the status of antibiotic use and clinical outcomes in patients with postoperative meningitis, including antibiotic prophylaxis, empirical, definitive therapy and mortality. Antibiotics were employed by the neurosurgical doctors according to local or international common standards and antimicrobial susceptibility testing. Twenty-one characteristics of the postoperative meningitis patients were extracted from the clinical database for risk factor evaluation, including patients' routine information (age, male\%), fever $\left(>38^{\circ} \mathrm{C}\right)$, assist mechanical ventilation (AMV), bacteraemia, craniotomy, CSF leakage, diabetes mellitus, EVD, Glasgow Coma Scale (GCS), hospitalacquired pneumonia, hypertension, intensive care unit (ICU) admission, lumbar drainage (LD), long-time surgery duration(>180 min), length of hospital stay (LOS), malignancy, postoperative infection time, reoperation, surgical wound classification, and time of cure of infection.

\section{Statistical analysis}

All of the variables differences were evaluated by univariate analysis. Of them, the categorical variables were 
assessed by Pearson's chi-squared test. Quantitative data were assessed using Student's t-test or one-way variance analysis test, and abnormally distributed quantitative variables were processed using Kruskal-Wallis or MannWhitney $U$ test. Binary logistic algorithm was built to evaluate differences between the EPE and NEPE postoperative meningitis patients. Any variables with $P<0.1$ in the univariate analysis were carried forward in binary logistic regression algorithm to analyse the independent risk factor for EPE postoperative meningitis. Significance was defined as a $P<0.05$, and calibration was analysed by Hosmere Lemeshow (H-L) test for goodness-of-fit. Statistical analyses were carried out by SPSS 22.0 (IBM, New York, USA). The graph was performed using Prism 7.0 (Graphpad, San Diego, USA).

\section{Result}

Patients

Over the 6 years of the study, a total of 51,227 neurosurgery patients and 4198 postoperative meningitis patients were included in the four centres described above. The infection rate was $8.2 \%(4198 / 51,227)$. Two hundred seventy-two cases of Enterobacteriaceae postoperative meningitis were recorded. Of them, 52 were excluded based on criteria (Fig. 1).

\section{Microbiology}

The distribution of Enterobacteriaceae is shown in Table 1. From that, Klebsiella pneumoniae has the highest proportion $(40.9 \%, 90 / 220)$, followed by Escherichia coli $(17.3 \%$, $38 / 220)$, Enterobacter aerogenes $(10.0 \%, 22 / 220)$, and Enterobacter cloacae (9.1\%, 20/220). The antimicrobial susceptibility test of the Enterobacteriaceae is shown in Fig. 2. The proportion of EPE was 35.5\%. In carbapenem, sensitivity to meropenem and imipenem were both $85.0 \%$. Among the $78 \mathrm{EPE}, 67$ isolates of ESBLrelated genes were detected by MNCP, and the $b l a_{S H V}$ gene is the most frequent ESBL-related gene. Majority $(58.2 \%, 39 / 67)$ of the gene-harbouring EPE contained multiple genes, and the most frequent ESBL-related gene combination of EPE is $b l a_{S H V}+$ $b l a_{T E M}+b l a_{C T X-M-9}$. The whole distribution of the genes is shown in Fig. 3-A. Also, we classified all of the $67 \mathrm{EPE}$ into 3 groups, including $K$. pneumonia, E. coli and others. The numbers of each groups' genes are shown in Fig. 3-B.

\section{Therapy and clinical outcomes of patients with Enterobacteriaceae postoperative meningitis}

Table 2 shows clinical therapy and outcomes of patients with Enterobacteriaceae postoperative meningitis. Of them 95.5\% (210/220), 94.6\% (208/220) and 97.7\% (215/ $220)$ of patients received antibiotic prophylaxis, empirical antibiotics medication and definitive therapy. Finally
Table 1 Distribution of Enterobacteriaceae Species in four neurosurgical centres

\begin{tabular}{llll}
\hline Enterobacteriaceae & EPE(78) & NEPE(142) & Total(220) \\
\hline Citrobacter koseri & $0(0.0 \%)$ & $4(2.8 \%)$ & $4(1.8 \%)$ \\
Enterobacter aerogenes & $6(7.7 \%)$ & $16(11.3 \%)$ & $22(10.0 \%)$ \\
Enterobacter cloacae & $4(5.1 \%)$ & $16(11.3 \%)$ & $20(9.1 \%)$ \\
Enterobacter gergoviae & $0(0.0 \%)$ & $1(0.7 \%)$ & $1(0.4 \%)$ \\
Enterobacter hormaechei & $0(0.0 \%)$ & $2(1.4 \%)$ & $2(0.9 \%)$ \\
Enterobacter sakazakii & $0(0.0 \%)$ & $1(0.7 \%)$ & $1(0.4 \%)$ \\
Escherichia coli & $20(25.6 \%)$ & $18(12.7 \%)$ & $38(17.3 \%)$ \\
Klebsiella oxytoca & $0(0.0 \%)$ & $11(7.8 \%)$ & $11(5.0 \%)$ \\
Klebsiella pneumoniae & $42(53.8 \%)$ & $48(33.8 \%)$ & $90(40.9 \%)$ \\
Morganella morganii & $0(0.0 \%)$ & $1(0.7 \%)$ & $1(0.4 \%)$ \\
Pantoea agglomerans & $2(2.6 \%)$ & $7(4.9 \%)$ & $9(4.1 \%)$ \\
Proteus mirabilis & $1(1.3 \%)$ & $0(0.0 \%)$ & $1(0.4 \%)$ \\
Proteus rettgeri & $0(0.0 \%)$ & $2(1.4 \%)$ & $2(0.9 \%)$ \\
Serratia marcescens & $2(2.6 \%)$ & $15(10.6 \%)$ & $17(7.7 \%)$ \\
Serratia plymuthica & $1(1.3 \%)$ & $0(0.0 \%)$ & $1(0.4 \%)$ \\
\hline
\end{tabular}

$83.6 \%(184 / 220)$ patients were cured in total, and $16.4 \%$ (36/220) patients died; among them, the mortality attributed to infection rate was $11.8 \%(26 / 220)$. There were no significant differences between the EPE and NEPE postoperative meningitis in the three treatment methods. However, in comparison with NEPE group, clinical outcome of mortality attribute to infection was significantly higher in EPE group (18.0\% VS 8.4\%, $\chi 2=4.358, P=0.049$ ).

\section{Univariate analysis of risk factors for EPE postoperative meningitis}

The main demographic and clinical characteristic data of EPE and NEPE postoperative meningitis groups are shown in Table 3. In univariate analysis of 21 factors in EPE- and NEPE-related postoperative meningitis patients, 4 factors were clinical significantly different $(P<0.05)$, including: AMV $(\mathrm{X} 2=0.007, \quad P=0.007)$, surgical wound classification $\left(x^{2}=5.265, P=0.024\right)$, craniotomy $(\mathrm{x} 2=14.675, \quad P<0.001)$ and malignancy $\left(x^{2}=4.466, P=0.048\right)$.

\section{Binary logistic analysis of risk factors for EPE postoperative meningitis}

We conducted a binary logistic analysis to evaluate the independent risk factor of EPE postoperative meningitis (Table 4). Firstly, we included all the factors with $P<0.1$ in the univariate analysis into the binary logistic analysis. Then, the H-L test of the model was calculated for calibration. All the variables embedded in the algorithm by binary logistic analysis were listed in Table 4. From that, craniotomy (odds ratio (OR) 2.583, 95\% confidence interval(C.I.) $1.274-5.235, P=0.008)$ and malignancy 


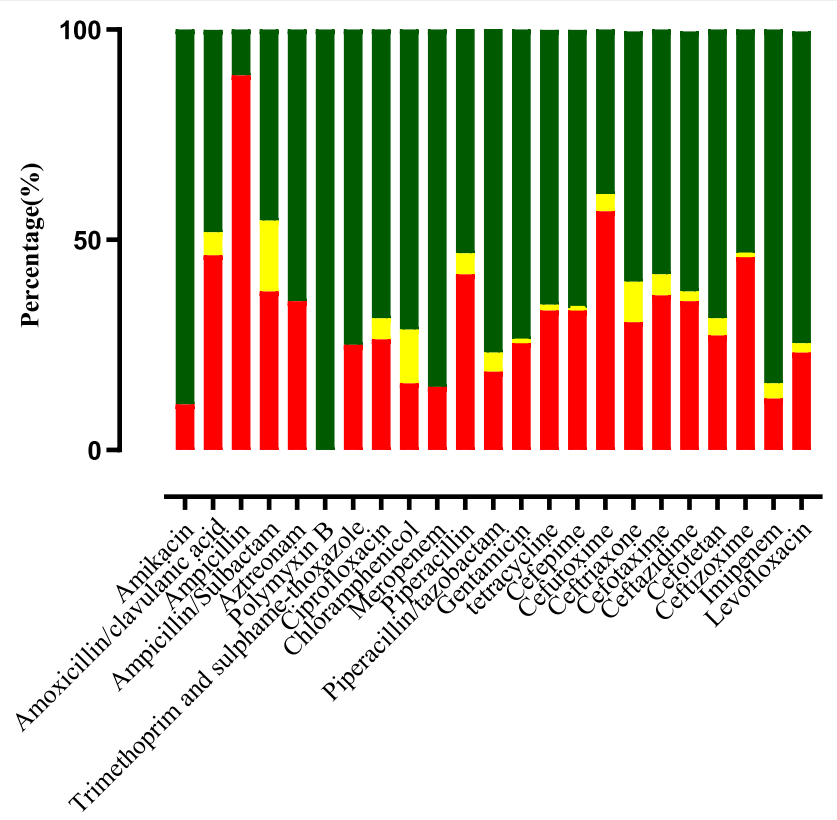

Fig. 2 Antimicrobial susceptibility test of Enterobacteriaceae enrolled in four neurosurgical centres

(OR 2.406, 95\% C.I. 1.299-4.456, $P=0.005$ ) were independent risk factors for EPE meningitis, and the $\mathrm{H}$-L test is $0.773(>0.05)$.

\section{Discussion}

In this multi-centre study, we conduct the largest neurosurgical individuals with Enterobacteriaceae postoperative meningitis up to now, including 220 adult patients during 2014-2019. Characteristics of the molecular epidemiology, and risk factors in EPE postoperative meningitis were screened. Of them, craniotomy (OR 2.583, 95\% C.I. 1.274-5.235, $P=0.008$ ) and malignancy (OR 2.406, 95\% C.I. 1.299-4.456, $P=0.005$ ) were independent risk factors for EPE postoperative meningitis, and the mortality attributed to infection between the two groups is significantly different. It was also confirmed that the majority of EPE contained more than one ESBL related gene, while $b l a_{S H V}+b l a_{T E M}+b l a_{C T X-M-9}$ is the most frequent gene combination.

Enterobacteriaceae is one of the critical pathogenic bacteria that cause nosocomial infections, occupying a large proportion of all pathogenic bacteria. As previously reported, EPE has played a vital role in nosocomial infection [23]. It has the properties of easy to acquire resistance genes (e.g., horizontal gene transfer) [24], and high pathogenicity [25]. It has strong drug resistance characteristics, and the incidence of ESBL production is $35.5 \%$, but the proportion of ESBL production by $K$. pneumoniae and E. coli is as high as 46.7 and $52.6 \%$. The WHO ranks EPE as the first priority of grade (critical), it has extensive drug resistance and is resistant to most $\beta$-lactam antibiotics
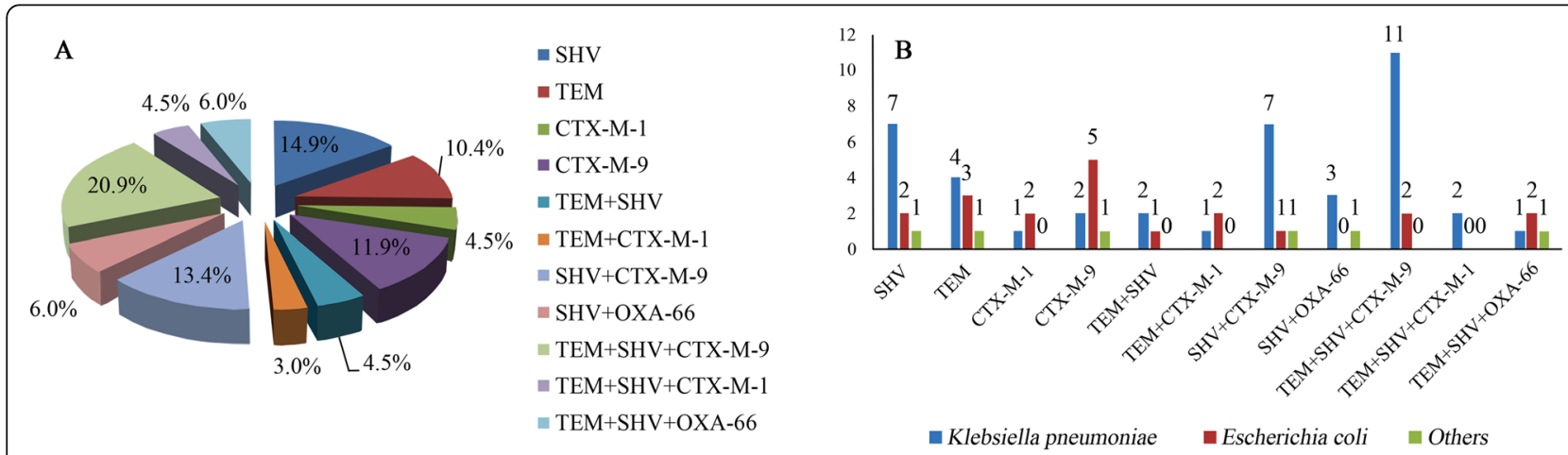

Fig. 3 Distribution of ESBL-related genes among the EPE isolates (a). Distribution of ESBL types carried by K. pneumoniae, E. coli and other EPE isolates (b) collected from 2014 to 2019 in four neurosurgical centres in China 
Table 2 Therapy and outcomes of EPE postoperative meningitis

\begin{tabular}{|c|c|c|c|c|c|}
\hline Antibiotics & Total (220) & EPE (78) & NEPE (142) & $x^{2}$ & $P$ \\
\hline Antibiotic prophylaxis & $210(95.4 \%)$ & $73(93.6 \%)$ & $133(93.7 \%)$ & - & 0.999 \\
\hline Ceftazidime & $13(5.9 \%)$ & $7(9.0 \%)$ & $6(4.2 \%)$ & 2.055 & 0.229 \\
\hline Ceftriaxone & $34(15.4 \%)$ & $14(18.0 \%)$ & $20(14.1 \%)$ & 0.589 & 0.440 \\
\hline Cefuroxime & $109(49.6 \%)$ & $38(48.7 \%)$ & $71(50.0 \%)$ & 0.596 & 0.460 \\
\hline Meropenem & $9(4.1 \%)$ & $3(3.8 \%)$ & $6(4.2 \%)$ & 0.018 & 0.999 \\
\hline Erythromycin & $13(5.9 \%)$ & $5(6.4 \%)$ & $8(5.6 \%)$ & 0.055 & 0.774 \\
\hline Cefoperazone/Sulbactam & $11(5.0 \%)$ & $2(2.6 \%)$ & $9(6.3 \%)$ & 1.512 & 0.334 \\
\hline Others & $17(7.7 \%)$ & $4(5.1 \%)$ & $13(9.2 \%)$ & 1.148 & 0.428 \\
\hline Received empirical antibiotics & $208(94.6 \%)$ & $73(93.6 \%)$ & 135 (95.1\%) & 0.241 & 0.758 \\
\hline Single antibiotics & 75 (34.1\%) & $23(29.5 \%)$ & $52(36.6 \%)$ & 1.010 & 0.365 \\
\hline Ceftriaxone & $11(5.0 \%)$ & $4(5.13 \%)$ & $7(4.9 \%)$ & 0.197 & 0.728 \\
\hline Meropenem & 46 (20.9\%) & $15(19.2 \%)$ & $31(21.8 \%)$ & 0.211 & 0.798 \\
\hline Cefuroxime & $4(1.8 \%)$ & $1(1.3 \%)$ & $3(2.1 \%)$ & 0.064 & 0.999 \\
\hline Vancomycin & $14(6.4 \%)$ & $3(3.8 \%)$ & $11(7.8 \%)$ & 0.691 & 0.529 \\
\hline Combination antibiotics (2) & $113(51.4 \%)$ & $42(53.8 \%)$ & $71(50.0 \%)$ & 0.466 & 0.560 \\
\hline Vancomycin + Meropenem & $96(43.6 \%)$ & $35(44.9 \%)$ & $61(43.0 \%)$ & 0.138 & 0.788 \\
\hline Vancomycin + Ceftazidime & $7(3.2 \%)$ & $3(3.8 \%)$ & $4(2.8 \%)$ & 0.103 & 0.710 \\
\hline Others & $10(4.6 \%)$ & $4(5.1 \%)$ & $6(4.2 \%)$ & 0.038 & 0.999 \\
\hline Combination antibiotics (3) & $28(12.7 \%)$ & $9(11.5 \%)$ & 19 (13.4\%) & 0.124 & 0.833 \\
\hline Vancomycin + Meropenem +Cefuroxime & $8(3.6 \%)$ & $3(3.8 \%)$ & $5(3.5 \%)$ & 0.147 & 0.999 \\
\hline Vancomycin + Meropenem +Tinidazole & $6(2.7 \%)$ & $3(3.8 \%)$ & $3(2.1 \%)$ & 1.116 & 0.352 \\
\hline Others & $14(6.4 \%)$ & $3(3.8 \%)$ & $11(7.8 \%)$ & 1.474 & 0.420 \\
\hline Received definitive therapy & $215(97.7 \%)$ & $74(94.9 \%)$ & $141(99.3 \%)$ & 4.436 & 0.055 \\
\hline Single antibiotics & $67(30.4 \%)$ & $19(24.4 \%)$ & $48(33.8 \%)$ & 1.584 & 0.220 \\
\hline Meropenem & $61(27.7 \%)$ & $16(20.5 \%)$ & $45(31.7 \%)$ & 1.519 & 0.341 \\
\hline Ceftriaxone & $4(1.8 \%)$ & $2(2.6 \%)$ & $2(1.4 \%)$ & 0.981 & 0.371 \\
\hline Colistin & $2(0.9 \%)$ & $1(1.3 \%)$ & $1(0.7 \%)$ & 0.475 & 0.490 \\
\hline Combination antibiotics (2) & $128(58.2 \%)$ & $48(61.5 \%)$ & $80(56.3 \%)$ & 1.331 & 0.306 \\
\hline Vancomycin + Meropenem & $105(47.7 \%)$ & 39 (50.0\%) & $66(46.5 \%)$ & 0.032 & 0.999 \\
\hline Vancomycin + Ceftazidime & $8(3.6 \%)$ & $3(3.8 \%)$ & $5(3.5 \%)$ & 0.001 & 0.999 \\
\hline Meropenem + Tigecycline & $8(3.6 \%)$ & $2(2.6 \%)$ & $6(4.2 \%)$ & 0.569 & 0.709 \\
\hline Others & $7(3.2 \%)$ & $4(5.1 \%)$ & $3(2.1 \%)$ & 1.219 & 0.424 \\
\hline Combination antibiotics (3) & $20(9.1 \%)$ & $7(9.0 \%)$ & $13(9.2 \%)$ & 0.003 & 0.999 \\
\hline Colistin+ Meropenem + Trimethoprim & $7(3.2 \%)$ & $2(2.6 \%)$ & $5(3.5 \%)$ & 0.196 & 0.999 \\
\hline Colistin+ Tigecycline + Meropenem & $6(2.7 \%)$ & $3(3.8 \%)$ & $3(2.1 \%)$ & 0.848 & 0.613 \\
\hline Others & $7(3.2 \%)$ & $2(2.6 \%)$ & $5(3.5 \%)$ & 0.196 & 0.999 \\
\hline \multicolumn{6}{|l|}{ Clinical Outcome } \\
\hline Improved and cured & $184(83.6 \%)$ & $62(79.5 \%)$ & $122(85.9 \%)$ & 1.520 & 0.254 \\
\hline Mortality attributed to infection & $26(11.8 \%)$ & $14(18.0 \%)$ & $12(8.4 \%)$ & 4.358 & 0.049 \\
\hline Mortality not attributed to infection & $10(4.6 \%)$ & $2(2.6 \%)$ & $8(5.6 \%)$ & 1.093 & 0.500 \\
\hline
\end{tabular}

except carbapenem. High rates of sensitivity were found against aminoglycoside; however, ototoxicity and nephrotoxicity of the aminoglycoside blocked clinical applications [26].
This study confirmed that the majority of EPEs does not pose single ESBL-resistance gene. The proportion of EPE with a single gene is $41.8 \%$. Among them, the bla $_{S H V}$ gene is the most frequent ESBL-related gene 
Table 3 Characteristics of patients and Univariate analysis between $f$ EPE and NEPE postoperative meningitis

\begin{tabular}{|c|c|c|c|c|c|}
\hline Characteristics & Total (220) & EPE (78) & NEPE (142) & $z / x^{2}$ & $P$ \\
\hline Age (years) & & & & 0.400 & 0.565 \\
\hline Median & 45 & 45 & 43 & & \\
\hline IQR & $30-55$ & $30-59$ & $31-52$ & & \\
\hline Male\% & $126(57.3 \%)$ & $49(62.8 \%)$ & $77(54.2 \%)$ & 1.520 & 0.255 \\
\hline Hypertension & $45(20.4 \%)$ & $18(23.1 \%)$ & $27(19.0 \%)$ & 0.511 & 0.489 \\
\hline Diabetes mellitus & $16(7.3 \%)$ & $5(6.4 \%)$ & $11(7.8 \%)$ & 0.133 & 0.793 \\
\hline Fever $\left(\mathrm{b} . \mathrm{t}>38^{\circ} \mathrm{C}\right)$ & $130(59.1 \%)$ & $42(53.8 \%)$ & $88(62.0 \%)$ & 1.375 & 0.254 \\
\hline LD & $99(45.0 \%)$ & $40(51.3 \%)$ & $59(41.3 \%)$ & 1.927 & 0.202 \\
\hline EVD & $113(51.4 \%)$ & $36(46.2 \%)$ & $77(54.2 \%)$ & 1.313 & 0.263 \\
\hline Long surgery duration (> $180 \mathrm{~min}$ ) & $126(57.3 \%)$ & $50(64.1 \%)$ & $76(53.5 \%)$ & 2.304 & 0.155 \\
\hline CSF Leakage & $48(21.8 \%)$ & $20(25.6 \%)$ & $28(19.7 \%)$ & 1.035 & 0.312 \\
\hline Reoperation & $56(25.4 \%)$ & $24(30.8 \%)$ & $32(22.5 \%)$ & 1.799 & 0.198 \\
\hline AMV & $72(32.7 \%)$ & $35(44.9 \%)$ & $37(26.1 \%)$ & 8.095 & 0.007 \\
\hline LOS (days) & & & & 1.326 & 0.198 \\
\hline Median & 35 & 38 & 34 & & \\
\hline IQR & $20-41$ & $20-42$ & $20-40$ & & \\
\hline Time of cure of infection (days) & & & & -1.620 & 0.626 \\
\hline Median & 13 & 13 & 13 & & \\
\hline IQR & $8-20$ & $7-18$ & $8-22$ & & \\
\hline Surgical wound classification & & & & 5.265 & 0.024 \\
\hline Clean (I) & $116(52.7 \%)$ & $51(65.4 \%)$ & $70(49.3 \%)$ & & \\
\hline Clean-contaminate (II) & $104(47.3 \%)$ & $27(34.6 \%)$ & $72(51.7 \%)$ & & \\
\hline Craniotomy & $114(51.8 \%)$ & $54(69.2 \%)$ & $60(42.2 \%)$ & 14.675 & $<0.001$ \\
\hline GCS & & & & -1.984 & 0.232 \\
\hline Median & 8 & 8 & 9 & & \\
\hline IQR & $6-12$ & $5-10$ & $7-12$ & & \\
\hline Postoperative infection time & & & & 1.284 & 0.366 \\
\hline Median & 7 & 8 & 7 & & \\
\hline IQR & $4-13$ & $4-14$ & $3-12$ & & \\
\hline ICU admission & $89(40.4 \%)$ & $37(47.4 \%)$ & $52(36.6 \%)$ & 2.445 & 0.151 \\
\hline Malignancy & $103(46.8 \%)$ & $44(56.4 \%)$ & $59(41.6 \%)$ & 4.466 & 0.048 \\
\hline Bacteraemia & $49(22.3 \%)$ & $19(24.4 \%)$ & $30(21.1 \%)$ & 0.304 & 0.613 \\
\hline Hospital-acquired pneumonia & $67(30.4 \%)$ & $27(34.6 \%)$ & $40(28.2 \%)$ & 0.988 & 0.359 \\
\hline
\end{tabular}

harboured by Enterobacteriaceae strains in the four centres of China during the past 6 years. ESBL-related genes are distributed differently around the world. Similar to our findings, one report conducted by Yahaya al [27]

Table 4 Binary logistic analysis of risk factors for EPE postoperative meningitis (OR: odds ratio; C.I.: confidence interval; H-L: Hosmere Lemeshow)

\begin{tabular}{lllll}
\hline Variables & $\boldsymbol{P}$ & OR & 95\% C.I. & H-L test \\
\hline Surgical wound classification & 0.703 & 1.134 & $0.594-2.169$ & 0.773 \\
Craniotomy & 0.008 & 2.583 & $1.274-5.235$ & \\
Malignancy & 0.005 & 2.406 & $1.299-4.456$ & \\
AMV & 0.123 & 1.652 & $0.873-3.127$ & \\
\hline
\end{tabular}

shows that bla $_{S H V}(36.4 \%)$ was the most frequent genotype in EPE, followed by $b l a_{T E M}(31.4 \%)$ and $b l a_{C T X-M}$ (27.3\%). In a previous analysis of ESBL carriage of Enterobacteriaceae, $b l a_{C T X-M-15}$ was the dominant ESBLproducing gene in all European countries except Greece, where bla $a_{S H V}$ were more common [28]. In the Netherlands, it's reported that $b l a_{C T X-M-1}$ was the predominant gene [29]. Previously studies above certified 
that predominance gene varied in different regions and probably determine the resistance phenotypes of the microorganisms. Further, the dominant genotypes of distinct EPE are different; For example, the highest genotype proportion of $K$. pneumoniae is bla $a_{S H V}$, and that of E. coli is bla $a_{C T X-M-15}$. Meanwhile, it was reported that EPE always carried various ESBL-related genes other than monogenotype [30]. The most frequent ESBL-related gene combination of EPE is $b l a_{S H V}+b l a_{T E M}+b l a_{C T X-M-9}(20.9 \%)$, followed by bla $a_{S H V}+b l a_{C T X-M-9}(13.4 \%)$, and the possible reason as follows: Firstly, plasmids possessing $b l a_{\text {СТХ-M }}$ genotypes are admitted to possessing other ESBL-related genes transmitting resistance to a series of antibiotics. Secondly, single replicon in distinct resistance gene location may lead to co-selection and may contribute to the dissemination [31].

The second- or third-generation cephalosporins were employed as antibiotic prophylaxis for postoperative meningitis patients ahead of the neurosurgery, which can prevent the invasion of pathogenic bacteria during the operation. In the empirical treatment, there are more antibiotics for selection, but vancomycin+meropenem is the main choice. This is because neurosurgery is generally complicated, and the use of the most effective antibiotics, such as carbarpenem, can most likely reduce the infection rate. In the definitive therapy, small percentage of patient population received monotherapy with meropenem. Carbarpenem seems to be the most frequently used antibiotic to cure EPE infections. Practice guidelines for management of ventriculitis/meningitis have been announced previously [32], a third-generation generation cephalosporin, such as ceftriaxone is endorsed for NEPE meningitis, while meropenem is endorsed as the first-line drugs target on EPE meningitis by general guidelines [33, 34].

Nevertheless, carbapenems should be used with caution because its overuse will generate acquisition of carbarpenem intermediate/resistant isolates by degrees. Also, resistance to third-generation cephalosporin in Enterobacteriaceae is always associated with ESBL, whereas resistance to carbapenems can be caused by production of an ESBL or plasmid mediated coded AmpC cephalosporinase combined with an efflux pump system or a decrease in outer membrane permeability [35-37]. It is reported that the mutation rate of the membrane permeability of Enterobacteriaceae is relatively high [38, 39], so when dealing with meningitis caused by EPE, even if it is treated with carbapenem antibiotics, good clinical outcomes may not be obtained. All of the 220 cases of Enterobacteriaceae in this study were sensitive to polymyxin $B$, which maybe the last line of defence against EPE or Carbapenem-resistant Enterobacteriaceae (CRE). It is reported that polymyxin B can be injected intrathecally in patients with severe Gram-negative bacteria [40], which maybe the ultimate choice for Enterobacteriaceae infection. However, polymyxin B causes nephrotoxicity, neuromuscular blockages and other adverse reactions, such as respiratory depression, and its application is limited to patients with critical disease. Therefore, to better deal with EPE postoperative meningitis, prevention of infection is still one of the main choices.

At present, several studies have explored the risk factors of postoperative meningitis. However, most of them focused on the incidence and total risk factors of neurosurgical meningitis. For example, a case-control study reports that patients with EVD, LD and diabetes were risk factors of meningitis after neurosurgery [3]. Another study showed that, hydrocephalus, Koos grade IV, operative duration $>3 \mathrm{~h}$ and intraoperative bleeding volume $>400 \mathrm{ml}$ were significantly were independent risk factors of postoperative meningitis after microsurgery for vestibular schwannoma. Fewer studies have focused on clinical characteristics and risk factors, specifically for multidrug resistant bacterial meningitis. Pintado et al. conducted a comparative cohort study to evaluate the prognostic factors of methicillin-resistant Staphylococcus aureus meningitis and concluded that mortality was related to indwell of cerebrospinal devices (OR 7.9, 95\% CI 3.1-20.3, $P<0.001$ ) [2]. Yagel conducted a matched case-control study to evaluate the bacteraemia caused by EPE and NEPE, and the result showed that Gramnegative bacteria have statistically significantly different factors involved in successful and failed treatment, including pathogen types, highest body temperature in the first $24 \mathrm{~h}$ of symptoms, CSF glucose content and meropenem susceptibility [41]. In this study, 21 variables were evaluated and binary logistic analysis of risk factors indicating that craniotomy and malignancy are individual independent risk factors of EPE postoperative meningitis. For craniotomy and malignancy patients, surgical operation is complicated, and the prognosis and the patient's own immunity is poor, which may lead to a high incidence of infection in patients. In addition, patients with malignancy have adopted high-level preoperative and empirical treatment [42], which may induce resistance to Enterobacteriaceae. Also, due to poor patient prognosis, the proportion of patients who gradually received highgrade antibiotics is high, and NEPE that cannot infect the patient's central nervous system directly may lead to Enterobacteriaceae meningitis.

Some limitations still exist in this study. First, this is a retrospective study, and the conclusion mostly depends on the accuracy of the data in hospital, which may result in selection bias, although we did a prospective genetic study of Enterobacteriaceae. Second, we did not include all clinical variables related to meningitis, such as grade of the tumors, multiple catheter insertion, and primary 
clinical laboratory tests were not embedded. In our next study, we will conduct a prospective study to include more neurosurgical centres (6-8) and patients (300500 ) and strive to achieve a universal risk factor assessment algorithm across China, creating a more objective risk factor assessment and prediction of EPE postoperative meningitis.

\section{Conclusion}

To our knowledge, this study is the first one to conduct a multi-centre molecular and comparative cohort study of EPE postoperative meningitis. Enterobacteriaceae postoperative meningitis is a relatively serious clinical challenge worldwide. We have determined the characteristics of the Enterobacteriaceae, molecular epidemiology and evaluated the risk factors and treatment of postoperative meningitis. Craniotomy and malignancy were determined to be independent risk factors for EPE postoperative meningitis, and it is necessary to pay attention to prevention and treatment clinically.

\section{Abbreviations}

EPE: ESBL-producing Enterobacteriaceae; CSF: cerebrospinal fluid;

EVD: external ventricular drain; MIC: microdilution method; CLSI: Clinical and Laboratory Standards Institute; NEPE: non-ESBL-producing Enterobacteriaceae; MNCP: micro/nanofluidic chip platform; GCS: Glasgow Coma Scale; ICU: intensive care unit; LD: lumbar drainage; LOS: length of hospital stay; AMV: assist mechanical ventilation; H-L: Hosmere Lemeshow

\section{Acknowledgements}

I want to take this chance to thanks to Yijun Shi, Yan Zhang, they give me many academic and precious suggestions at this section and helps me to correct my paper.

\section{Authors' contributions}

Conception and design of study: GJZ, LNZ, JY. Data collection: LYQ, MMC, HTS, YFC. Analysis and/or interpretation of data: CHL, YMC. Drafting the manuscript: GHZ, HL. All authors have read and approved the manuscript.

\section{Funding}

This study was supported by research grant: QML20180502, Beijing Municipal Administration of Hospitals. The fund supported the detection of all drug resistance genes in this study.

\section{Availability of data and materials}

The datasets used and/or analysed during this study are available from the corresponding author on reasonable request.

\section{Ethics approval and consent to participate}

This study was approved by the ethical committee of Beijing Tiantan Hospital and Capital Medical University (Approved Number: KY-2019-095-03). Since this study is a retrospective study, an ethical review was applied to waive the patient's informed consent.

\section{Consent for publication}

Not applicable.

\section{Competing interests}

On behalf of all authors, the corresponding author states that there is no competing interests.

\section{Author details}

'Department of Clinical Diagnosis, Laboratory of Beijing Tiantan Hospital and Capital Medical University, NO. 119 Nansihuan West road, Fengtai district, Beijing, China. ${ }^{2}$ Daqing Oilfield General Hospital Clinical Laboratory, No. 9
Zhongkang Street, Saltu District, Daqing, China. ${ }^{3}$ Department of Clinical Diagnosis, Laboratory of Sanbo Brain Hospital and Capital Medical University, NO.50 Yikesong Road, Haidian District, Beijing, China. ${ }^{4}$ Department of Clinical Diagnosis, Laboratory of the Second People's Hospital of Guiyang, Guiyang, China.

Received: 25 September 2020 Accepted: 11 January 2021

Published online: 19 January 2021

\section{References}

1. Farina J, Colque ÁM, Del Castillo M, Cremona A, Cornistein W, Staneloni MI. [Post-neurosurgical infections. Update and intersociety recommendations]. Medicina (B Aires). 2019. 79(6): 483-492.

2. Pintado V, Pazos R, Jiménez-Mejías ME, et al. Staphylococcus aureus meningitis in adults: a comparative cohort study of infections caused by meticillin-resistant and meticillin-susceptible strains. J Hosp Infect. 2019; 102(1):108-15.

3. Chen C, Zhang B, Yu S, et al. The incidence and risk factors of meningitis after major craniotomy in China: a retrospective cohort study. PLoS One. 2014;9(7):e101961.

4. Valentini LG, Casali C, Chatenoud L, Chiaffarino F, Uberti-Foppa C, Broggi G. Surgical site infections after elective neurosurgery: a survey of 1747 patients. Neurosurgery. 2008;62(1):88-95 discussion 95-6.

5. National Nosocomial Infections Surveillance System. National Nosocomial Infections Surveillance (NNIS) system report, data summary from January 1992 through June 2004, issued October 2004. Am J Infect Control. 2004; 32(8):470-85.

6. Strahm C, Albrich WC, Zdravkovic V, Schöbi B, Hildebrandt G, Schlegel M. Infection rate after cranial neurosurgical procedures: a prospective singlecenter study. World Neurosurg. 2018;111:e277-85.

7. Jain A, Arora N, Meher R, Passey JC, Bansal R. Intracranial complications of CSOM in pediatric patients: a persisting problem in developing countries. Int J Pediatr Otorhinolaryngol. 2017;100:128-31.

8. Antonioli P, Bolognesi N, Valpiani G, et al. A 2-year point-prevalence surveillance of healthcare-associated infections and antimicrobial use in Ferrara University hospital. Italy BMC Infect Dis. 2020;20(1):75.

9. Karanika S, Karantanos T, Arvanitis M, Grigoras C, Mylonakis E. Fecal colonization with extended-spectrum Beta-lactamase-producing Enterobacteriaceae and risk factors among healthy individuals: a systematic review and Metaanalysis. Clin Infect Dis. 2016;63(3):310-8.

10. Organization $\mathbf{W H}$. Global priority list of antibiotic-resistant bacteria to guide research, discovery, and development of new antibiotics. Geneva: $\mathrm{WHO}$; 2017. There is no corresponding record for this reference [Google Scholar] 2017

11. Li $X, X u X$, Yang $X$, et al. Risk factors for infection and/or colonisation with extended-spectrum $\beta$-lactamase-producing bacteria in the neonatal intensive care unit: a meta-analysis. Int J Antimicrob Agents. 2017;50(5):622-8.

12. Peña C, Pujol M, Ricart A, et al. Risk factors for faecal carriage of Klebsiella pneumoniae producing extended spectrum beta-lactamase (ESBL-KP) in the intensive care unit. J Hosp Infect. 1997:35(1):9-16.

13. Bradford PA. Extended-spectrum beta-lactamases in the 21 st century: characterization, epidemiology, and detection of this important resistance threat. Clin Microbiol Rev. 2001;14(4):933-51 table of contents.

14. Rice LB. Successful interventions for gram-negative resistance to extendedspectrum beta-lactam antiobiotics. Pharmacotherapy. 1999. 19(8 Pt 2): 120S-128S; discussion 133S-137S

15. Tosa M, Aihara M, Murakami J. Extended-spectrum Beta-lactamaseproducing Escherichia coli meningitis that developed from otitis media with Cholesteatoma. Intern Med. 2018:57(21):3199-204.

16. Guo W, Guo SC, Li M, Li LH, Qu Y. Successful treatment of extensively drugresistant Acinetobacter baumannii ventriculitis with polymyxin $B$ and tigecycline- a case report. Antimicrob Resist Infect Control. 2018;7:22.

17. Horan TC, Gaynes RP, Martone WJ, Jarvis WR, Emori TG. CDC definitions of nosocomial surgical site infections, 1992: a modification of CDC definitions of surgical wound infections. Infect Control Hosp Epidemiol. 1992;13(10):606-8.

18. Kourbeti IS, Vakis AF, Ziakas $P$, et al. Infections in patients undergoing craniotomy: risk factors associated with post-craniotomy meningitis. J Neurosurg. 2015;122(5):1113-9.

19. Yagel Y, Nativ H, Riesenberg K, Nesher L, Saidel-Odes L, Smolyakov R. Outcomes of UTI and bacteriuria caused by ESBL vs. non-ESBL 
Enterobacteriaceae isolates in pregnancy: a matched case-control study. Epidemiol Infect. 2018;146(6):771-4.

20. Amin H, Zafar A, Ejaz H, Jameel NU. Phenotypic characterization of ESBL producing Enterobacter cloacae among children. Pak J Med Sci. 2013;29(1):144-7.

21. Zheng G, Zhang Y, Zhang L, et al. Evaluation of a micro/nanofluidic chip platform for diagnosis of central nervous system infections: a multi-center prospective study. Sci Rep. 2020;10(1):1568.

22. Zhang G, Zheng G, Zhang Y, Ma R, Kang X. Evaluation of a micro/ nanofluidic chip platform for the high-throughput detection of bacteria and their antibiotic resistance genes in post-neurosurgical meningitis. Int J Infect Dis. 2018;70:115-20

23. Delaere L, Rondelet B, Dransart C, et al. NOSOCOMIAL OUTBREAK OF ESBLPRODUCING ENTEROBACTER cloacae AMONG CARDIO-1. 2019

24. Sonnevend A, Yahfoufi N, Ghazawi A, Jamal W, Rotimi V, Pál T. Contribution of horizontal gene transfer to the emergence of VIM- 4 carbapenemase producer Enterobacteriaceae in Kuwait. Infect Drug Resist. 2017;10:469.

25. Shields RK, Potoski BA, Haidar G, et al. Clinical outcomes, drug toxicity, and emergence of ceftazidime-avibactam resistance among patients treated for carbapenem-resistant Enterobacteriaceae infections. Clin Infect Dis. 2016; 63(12):1615.

26. Vicente-Vicente L, Casanova AG, Hernández-Sánchez MT, Pescador M, López-Hernández FJ, Morales Al. A systematic meta-analysis on the efficacy of pre-clinically tested nephroprotectants at preventing aminoglycoside nephrotoxicity. Toxicology. 2017;377:14.

27. Mohammed Y, Gadzama GB, Zailani SB, Aboderin AO. Characterization of extended-Spectrum Beta-lactamase from Escherichia coli and Klebsiella species from north eastern Nigeria. J Clin Diagn Res. 2016;10(2):DC07-10.

28. Kazmierczak KM, de Jonge B, Stone GG, Sahm DF. Longitudinal analysis of ESBL and carbapenemase carriage among Enterobacterales and Pseudomonas aeruginosa isolates collected in Europe as part of the International Network for Optimal Resistance Monitoring (INFORM) global surveillance programme, 2013-17. J Antimicrob Chemother. 2020;75(5):116573.

29. van Hoek A, Veenman C, Florijn A, et al. Longitudinal study of ESBL Escherichia coli carriage on an organic broiler farm. J Antimicrob Chemother. 2018;73(12):3298-304

30. Bali EB, Acik L, Sultan N. Phenotypic and molecular characterization of SHV, TEM, CTX-M and extended-spectrum beta-lactamase produced by Escherichia coli, Acinobacter baumannii and Klebsiella isolates in a Turkish hospital. Afr J Microbiol Res. 2010;4(8):650.

31. Cantón R, Coque TM. The CTX-M $\beta$-lactamase pandemic. Curr Opin Microbiol. 2006;9(5):466.

32. Tunkel AR, Hartman BJ, Kaplan SL, et al. Practice guidelines for the management of bacterial meningitis. Clin Infect Dis. 2004:39(9):1267-84.

33. Tunkel AR, Hasbun R, Bhimraj A, et al. 2017 Infectious Diseases Society of America's clinical practice guidelines for healthcare-associated Ventriculitis and meningitis. Clin Infect Dis. 2017:64(6):e34-65.

34. van de Beek D, Cabellos C, Dzupova O, et al. ESCMID guideline: diagnosis and treatment of acute bacterial meningitis. Clin Microbiol Infect. 2016; 22(Suppl 3):S37-62.

35. Bush K. Past and present perspectives on $\beta$-lactamases. Antimicrob Agents Chemother. 2018;62(10):S37-62.

36. Jacoby GA, Mills DM, Chow N. Role of beta-lactamases and porins in resistance to ertapenem and other beta-lactams in Klebsiella pneumoniae. Antimicrob Agents Chemother. 2004;48(8):3203-6.

37. Xu Y, Niu H, Hu T, et al. High expression of Metallo- $\beta$-lactamase contributed to the resistance to Carbapenem in clinical isolates of Pseudomonas aeruginosa from Baotou, China. Infect Drug Resist. 2020;13:35-43.

38. Pagès J, Peslier $\mathrm{S}$, Keating $\mathrm{TA}$, et al. Role of the outer membrane and porins in susceptibility of $\beta$-lactamase-producing Enterobacteriaceae to ceftazidime-avibactam. Antimicrob Agents Chemother. 2016;60:1349

39. Davin-Regli A. Antimicrobial drug efflux pumps in Enterobacter and Klebsiella. Efflux-mediated antimicrobial resistance in Bacteria; 2016.

40. Abad-Restrepo J, Díaz-Díaz A, Osorio-Cadavid N. Post-surgical ventriculitis due to extensively resistant Pseudomonas aeruginosa treated with intrathecal colistin. Pediatric case report and literature review. Rev Chil Infectol. 2018;35(3):321-5.

41. Chen Y, Li F, Zhu M, Liu L, Luo Y. Outcome and factors of patients with nosocomial meningitis by multi-drug-resistant gram-negative bacteria in a tertiary hospital in China: a retrospective study. Br J Neurosurg. 2020;34(3): $324-8$.
42. De la Garza-Ramos R, Kerezoudis P, Tamargo RJ, et al. Surgical complications following malignant brain tumor surgery: an analysis of 2002-2011 data. Clin Neurol Neurosurg. 2016;140:6.

\section{Publisher's Note}

Springer Nature remains neutral with regard to jurisdictional claims in published maps and institutional affiliations.

\section{Ready to submit your research? Choose BMC and benefit from:}

- fast, convenient online submission

- thorough peer review by experienced researchers in your field

- rapid publication on acceptance

- support for research data, including large and complex data types

- gold Open Access which fosters wider collaboration and increased citations

- maximum visibility for your research: over $100 \mathrm{M}$ website views per year

At BMC, research is always in progress.

Learn more biomedcentral.com/submissions 